\title{
ФАКТОРЫ РИСКА СНИЖЕНИЯ ТРАБЕКУЛЯРНОГО КОСТНОГО ИНДЕКСА У ЖЕНЩИН В ПОСТМЕНОПАУЗЕ С САХАРНЫМ ДИАБЕТОМ 2 ТИПА
}

\author{
Фазуллина О.Н., Корбут А.И., Климонтов В.В.
}

Научно-исследовательский институт клинической и экспериментальной лимфологии - филиал Федерального государственного бюджетного научного учреждения «Федеральный исследовательский иентр Институт цитологии и генетики Сибирского отделения Российской академии наук», Новосибирск

ЦЕЛЬ: выделить факторы, ассоциированные со снижением трабекулярного костного индекса (ТКИ), у женщин с сахарным диабетом (СД) 2 типа, находящихся в постменопаузе.

МАТЕРИАЛЫ И МЕТОДЫ: дизайн: одномоментное поперечное исследование. Включены 140 женщин в возрасте от 50 до 75 лет (медиана 67 лет) с СД 2 типа длительностью не менее 1 года (медиана 15 лет), в постменопаузе (медиана 17 лет). Критериями исключения являлись заболевания и состояния, являющиеся факторами риска вторичного остеопороза, а также прием медикаментов, оказывающих влияние на процессы костного ремоделирования. Все обследованные находились на сахароснижающей терапии, инсулинотерапию получали 62,2\% ( $\mathrm{n=87}$ ) больных. Избыточную массу тела имели 27 (19,3\%) больных, ожирение - 103 (73,6\%) женщины, медиана индекса массы тела (ИМТ) составила 32,4 кг/м². Уровень гликированного гемоглобина варьировал от 5,8 до 13,3\% (медиана - 8,9\%). Исследование минеральной плотности костной ткани (МПК), определение Т-критерия, параметров композитного состава тела (КСТ) выполнено на рентгеновском денситометре «Lunar Prodigy Advance», GE, США). С помощью программы TBS iNsight версия 3.0.2.0 рассчитан ТКИ. Статистическая обработка произведена с помощью программ STATISTICA 10 (StatSoftInc, США) и SPSS Statistics 26.0 (IMB, США).

PЕзУЛЬТАТЫ: на основании Т-критерия пациентки распределились следующим образом: остеопороз выявлен у 17 (12,2\%), остеопения - у 65 (46,4\%), нормальная МПК - у $58(41,4 \%)$ обследованных. Снижение ТКИ $\leq 1,31$ выявлено у 60,7\% $(n=85)$ женщин, при этом низкие значения ТКИ имелись у 48,3\% женщин с нормальной МПК. Частота встречаемости низких значений ТКИ увеличивалась по мере снижения МПК (67,7\% у больных с остеопенией и 76,5\% в группе остеопороза). Показана отрицательная ассоциация возраста и ТКИ ( $r=-0,34 ; p<0,001)$, положительная связь ТКИ и ИМТ ( $r=0,26 ; p=0,005)$. При анализе параметров КСТ с ТКИ положительно коррелировала масса жировой ткани на бедрах $(r=0,25, p=0,05)$. По данным ROC-анализа, включающего основные клинические параметры, а также данные КCT как независимые переменные, выделены «отрезные точки» значений факторов риска снижения ТКИ, для них рассчитано отношение шансов (ОШ), 95\% доверительный интервал (ДИ). Предикторами снижения ТКИ в этой группе оказались: возраст старше 65 лет (ОШ 3,53, ДИ 1,80-6,93, p=0,0002), ИМТ <32,5 кг/м² (ОШ 2,12, ДИ 1,11-4,07, p=0,02), длительность СД 2 типа $\geq 13$ лет (ОШ 3,34, ДИ 1,71-6,51, p=0,0004), длительность постменопаузы $\geq 15$ лет (ОШ 3,07, ДИ 1,38-6,81, p=0,006), снижение массы мышечной ткани <47,6 кг (ОШ 1,95, 95\% ДИ 1,02-3,73, p=0,04).

ВЫВОдЫ: предикторами снижения ТКИ у женщин с СД 2 типа в постменопаузе являются пожилой возраст, длительность СД и постменопаузы, отсутствие ожирения, относительно низкая масса мышечной ткани.

КЛЮЧЕВЫЕ СЛОВА: трабекулярный костный индекс; сахарный диабет 2 mипа; композитный состав тела. 